\title{
Getting value today and incentivising for the future: Pharmaceutical development and healthcare policies
}

\author{
KASPER MUNK JOHANNESEN ${ }^{1,2, *}$ \\ MARTIN HENRIKSSON ${ }^{2}$ \\ ${ }^{1}$ Center for Medical Technology Assessment, Linköping University, Sweden \\ ${ }^{2}$ Department of Health Economics, AstraZeneca Nordic, Södertälje, Sweden
}

\begin{abstract}
To manage the challenge of limited healthcare resources and unlimited demand for healthcare, decision makers utilise a variety of demand side policies, such as health technology appraisals and international reference pricing to regulate price and utilisation. By controlling price and utilisation demand side policies determine the earnings potential, and hence the incentives to invest in research and development (R\&D) of new technologies. However, the impact of demand side policies on R\&D incentives is seldom formally assessed.

Based on the key assumption that intellectual property rights, i.e. patents, and expected rent are key drivers of pharmaceutical $R \& D$, this work outlines a framework illustrating the link between demand side policies and pharmaceutical R\&D incentives. By analysing how policies impact expected rent and consumer surplus, the framework is used to understand how commonly used demand side policies (including timing and length of reimbursement process, international reference pricing, parallel trade, and sequential adoption into clinical practice) may influence $R \& D$ incentives.

The analysis demonstrates that delayed reimbursement decisions as well as sequential adoption into clinical practise may in fact reduce both expected rent and consumer surplus. It is also demonstrated how international reference pricing is likely to increase consumer surplus at the expense of lower rent and thus lower R\&D incentives.

Although this work illustrates the importance of considering how demand side policies may impact long-term R\&D incentives, it is important to note that the purpose has not been to prescribe which demand side policies should be utilised or how. Rather, the main contribution is to illustrate the need for a structured approach to the analysis of the complex, and at times highly politicised question of how demand side policies ultimately influence population health, both in the short and in the long term.
\end{abstract}

JEL classification: I18, F13, L12, O30

Key words: pharmaceutical market, pharmaceutical regulation, $R \& D$ incentives, intellectual property rights

\section{Introduction}

Pharmaceutical treatments constitute around $17 \%$ of healthcare spending in OECD countries and 12\% in Sweden (LIF, 2014; OECD, 2013), and have been one of several factors contributing to longevity and morbidity improvement over the last decades

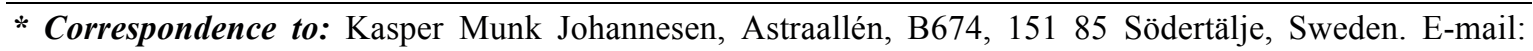


(Lichtenberg and Pettersson, 2014; Lichtenberg, 2004). However, technological innovation and development are also key challenges for healthcare financing, and healthcare decision makers inevitably need to prioritise what currently available treatments should be funded (Appleby, 2013; Claxton et al., 2002).

Pharmaceutical demand side policies are a commonly used mechanism to regulate price and utilisation of pharmaceutical technologies (Kanavos, 2003; Kanavos et al., 2010; Leopold et al., 2012; Vogler et al., 2011). Examples of such regulation in the Nordic countries are international reference pricing (Leopold et al., 2012) and value based pricing (Kanavos et al., 2010). As demand side policies regulate price and utilisation and hence determine earnings on pharmaceuticals, they are clearly interlinked with pharmaceutical research and development (R\&D) incentives (Danzon and Towse, 2005; Grabowski and Vernon, 2000; Vernon, 2005). Demand side policies and policies to incentivise R\&D are, nevertheless, often discussed and analysed separately, and a coherent approach to analyse them jointly appears to be lacking. A structured approach may be particularly important given the highly politicised environment, where policies may focus on short-term optimisation with a risk of omitting the long-term implications.

In this paper we propose a conceptual framework that outlines a link between pharmaceutical demand side policies and R\&D incentives. The proposed framework is then used to analyse how certain commonly used demand side policies impact R\&D incentives.

The paper is structured as follows. The next section outlines the conceptual framework. In section three the implications of demand side policies for R\&D incentives is analysed. Section four introduces a global context to the analysis. The paper ends with a discussion and concluding remarks.

\section{Development and expected rent of pharmaceuticals}

\subsection{Pharmaceutical development}

The research and development of pharmaceuticals is challenging. Pharmaceutical products, e.g. pills and injections, are private goods; they cannot be used by another person once consumed by a given individual. In contrast, pharmaceutical technologies and discoveries are essentially informational/knowledge goods that can be classified as "global public goods" given their global accessibility, non-rival and non-excludable nature once developed (Kaul and Mendoza, 2003; Moon, 2008; Sandler, 1999) ${ }^{1}$.

The cost of developing a new pharmaceutical technology is substantial. Recent estimates point to US\$1,506 million (Mestre-ferrandiz et al., 2012). In contrast, the cost of producing pharmaceutical products is in general low. This is evident from the significant price reductions when generic competition enters the market post patent expiry, after which many products are sold at prices down to a few cents $(\$)$ per tablet ${ }^{2}$. Without restrictions on production or sales of pharmaceuticals, investors would be unable to cover the substantial development costs leading to a market failure of pharmaceutical development (Carlton and Perloff, 2005; Danzon et al., 2015). The global accessibility of

\footnotetext{
${ }^{1}$ It should be noted that the use of pharmaceutical technologies to produce pharmaceutical products are made "excludable" during the time of patent protection under the intellectual property rights regime. However, as outlined by Kaul \& Mendoza 2003 changing the non-rival and non-excludable nature of pharmaceutical technologies by utilising patents is a policy decision, and does not change the fact that these goods are fundamentally non-rival and non-excludable.

${ }^{2}$ This can for example be seen in the list of "preferred (generic) products" published by Tandvårds- och läkemedelsförmånsverket (TLV) in Sweden each month. www.tlv.se/apotek/utbyte-av-lakemedel-pa-apotek/periodens-varor/
} 
developed technologies further creates free-rider and collective action problems (Carlton and Perloff, 2005; Danzon and Towse, 2005; Grabowski, 2005).

Intellectual property rights, i.e. patents, are important for incentivising pharmaceutical R\&D (Carlton and Perloff, 2005; Danzon and Towse, 2005; Grootendorst and Edwards, 2014; Munos, 2009). Patents create a time limited monopoly for the sale of pharmaceutical products, providing the developers with the opportunity to cover their R\&D cost. Pharmaceutical R\&D investments will likely occur when the expected rent (during the time of patent protection) covers development costs and provides a competitive return on investment (Carlton and Perloff, 2005; Danzon and Towse, 2005; Grabowski, 2005). The assumption that R\&D incentives are largely driven by expected rent, and that expected rent in turn is dependent on demand side policies regulating price and utilisation, is the foundation of the framework outlined below.

It is important to note that patents are no first best solution given the inefficiency of monopoly pricing. Patents further lead to inequitable R\&D investments since they incentivise greater investment in development of treatments for diseases predominantly affecting citizens of developed countries (Civan and Maloney, 2006; Hubbard and Love, 2004; Kaul et al., 1999). Different remedial approaches to overcome these issues have been proposed including the compensation of producer for operating on a lower point on the demand curve and Ramsey pricing (Carlton and Perloff, 2005; Danzon and Towse, 2005; Persson et al., 2012). Promoting pharmaceutical R\&D through other means than intellectual property rights, e.g. innovation prizes and increased public funding has also been extensively discussed (Agitha, 2013; Carlton and Perloff, 2005; Dimasi and Grabowski, 2004; Grootendorst and Edwards, 2014; Hubbard and Love, 2004; Munos, 2009). The purpose of this work is, however, not to describe or analyse how to achieve optimal and equitable pharmaceutical R\&D investment levels, but rather to provide a framework and analysis of how demand side policies may influence R\&D investments under the currently utilised system of intellectual property rights.

\subsection{Pharmaceutical supply and demand}

Figure 1 outlines a stylised example of supply and demand for pharmaceutical products illustrating monopoly pricing (where marginal cost (MC) equals marginal revenue (MR)), and competitive pricing (where price equals marginal $\operatorname{cost}^{3}$ ). Under monopoly pricing producer surplus (PS) and consumer surplus (CS) will be equal to area $\mathrm{BCEP}^{\mathrm{M}}$ and $\mathrm{AEP}^{\mathrm{M}}$ in Figure 1, respectively. At competitive pricing producer and consumer surplus is equal to areas $\mathrm{BFP}^{\mathrm{C}}$ and $\mathrm{AFP}^{\mathrm{C}}$, respectively. Monopoly pricing leads to a deadweight loss (DL) as defined by areas CEF in figure 1 .

Demand curves, as exemplified by $\mathrm{D}$ in Figure 1, usually represent the quantity demanded by individuals across different prices, i.e. the number of individuals with a maximum willingness to pay exceeding specific prices. However, in most developed countries, healthcare interventions are mainly funded by third-party payers via insurance or otherwise collectively funded healthcare financing (OECD, 2013). The demand (curve)

\footnotetext{
${ }^{3}$ It has been argued that pharmaceutical pricing may be more in line with monopolistic competition given that alternative treatment strategies may limit producers ability to utilise monopoly pricing (Danzon and Towse, 2005). However, unless a technology with equal therapeutic properties exists then the availability of alternative and different treatments would be reflected in the demand curve under which the monopolistic producer maximises surplus with monopoly pricing. The framework in this work assumes monopolistic pricing and that alternative technologies are reflected in the demand curve and may therefore not be directly applicable to technologies in which introduction will lead to increased (monopolistic) competition. Monopoly pricing does nevertheless provide a good illustration of the economic problem investigated in this study.
} 
for pharmaceuticals within a collectively founded healthcare system therefore represents healthcare decision makers' demand for a technology at different prices. The demand (curve) for healthcare decision makers thus incorporates the (magnitude of) benefit provided by a technology and the willingness to pay for that benefit ${ }^{4}$.

Evidence on treatment benefits are most often estimated on an aggregated subgroup or total patients population level. Further, healthcare decision makers may not be able, or allowed to discriminate between individuals. Therefore, the demand (curve) for pharmaceutical technologies is likely to be of a stepwise nature, as detailed by for example Claxton 2007. Nevertheless, a simple linear demand curve, as presented in Figure 1, provides a good illustration of the economic problem.

\section{Figure 1: A stylised example of supply and demand illustrating monopoly and competitive pricing}

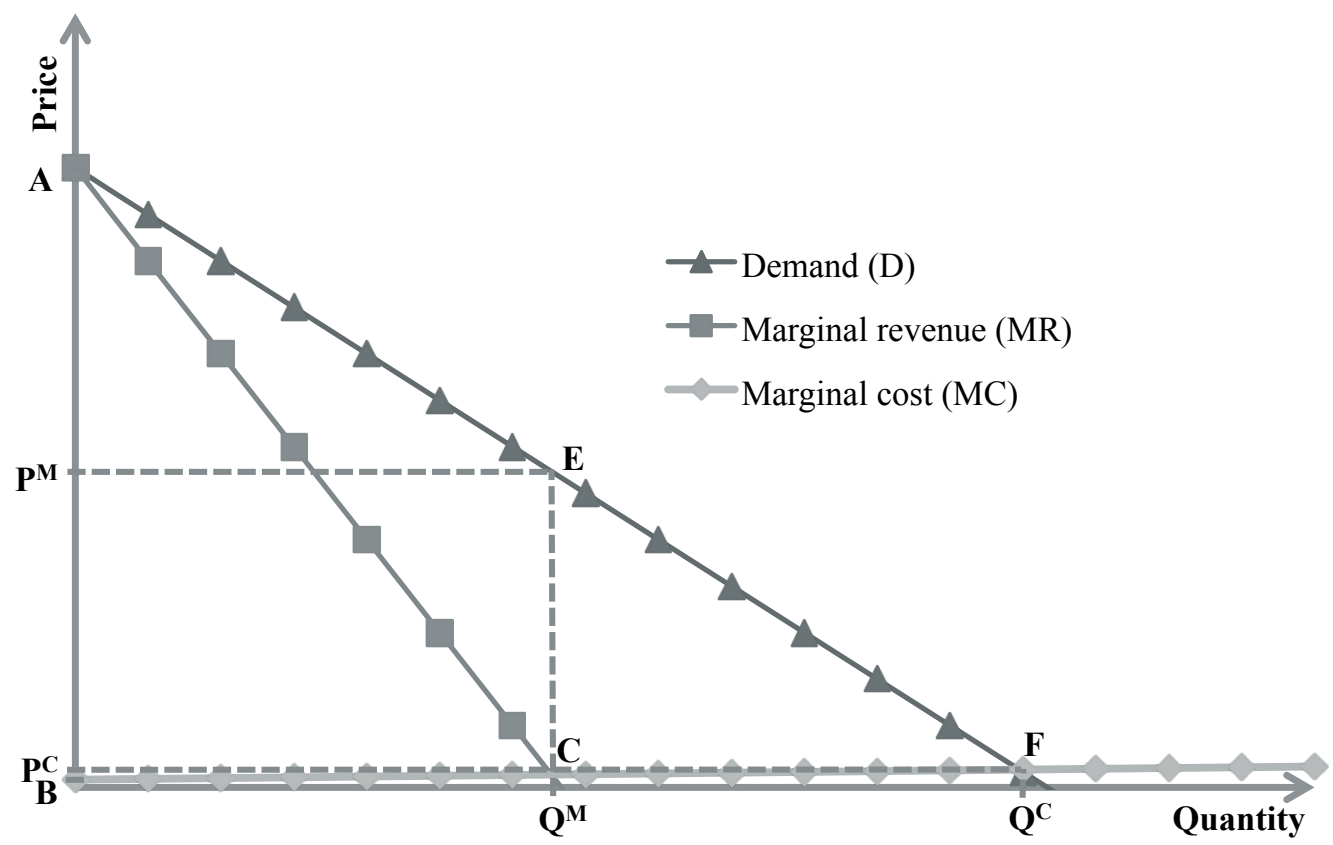

Note: Figure based on the numerical example outlined in Appendix 1.

\subsection{Expected rent}

The value of a pharmaceutical technology for producers and consumers during the time of patent protection is the producer and consumer surplus accumulated from time of marketing authorisation approval ( $\left.\mathrm{t}_{\mathrm{MAA}}\right)$ until patent expiry $\left(\mathrm{t}_{\mathrm{gx}}\right)$. Assuming that pharmaceutical developers are profit maximising entities, they will maximise producer surplus by utilising monopoly pricing.

Post patent expiry, it is assumed that generic competition will drive down the price to marginal cost thus decreasing producer surplus and increasing consumer surplus. The

\footnotetext{
${ }^{4}$ Willingness to pay includes both the value societies/insurers put on the benefit as well as opportunity cost. The opportunity cost can be represented by (i) the marginal rate of substitution between (health) benefit and consumption, (ii) the health/value provided by another medical technology that will be displaced by the introduction of a new treatment, i.e. the cost-effectiveness threshold, or (iii) a combination of the two, as described by for example Claxton et al. 2010. Hence, willingness to pay may vary and depend on the view of what constitutes opportunity cost.
} 
increase in consumer surplus is a result of a reduction in producer surplus and elimination of the deadweight loss of monopoly pricing. A mathematical expression and a graphical illustration of producer and consumer surplus, during and after patent protection, are provided in Table 1 and Figure 2, respectively. They follow from the assumption that a pharmaceutical technology is provided to individuals for whom it has been assessed to constitute a net gain. Figure 2 is based on a numerical example outlined in Appendix 1.

It is unclear whether the developer of a pharmaceutical technology will earn any of the remaining producer surplus post patent expiry, given the competition with other producers. Hence, in our framework we define expected rent for a pharmaceutical technology as (monopolistic) producer surplus during the time of patent protection, and our analysis focuses on how demand side policies impact expected rent and consumer surplus during the time of patent protection.

The relationship between expected rent and $R \& D$ incentives has been demonstrated in both theoretical and empirical studies, which have established two main ways in which rent impacts R\&D investments: (i) impact on earnings potential, i.e. expected rent, of future products; and (ii) impact on cash-flow, i.e. expected rent from currently utilised (and patented) products (Grabowski and Vernon, 2000; Malmberg, 2008; Vernon, 2005).

For ease of exposition the analysis in the following section estimates expected rent from time of marketing authorisation approval ( $t_{\mathrm{MAA}}$ ) and thus estimates demand side policies impact on expected rent of future pharmaceutical technologies. However, the analyses can easily be amended by substituting $t_{\text {MAA }}$ with $t_{x}$, where $t_{x}$ represents the current date or the time when a demand side policy is implemented.

Figure 2: Illustration of producer and consumer surplus during the time of market exclusivity ( $t_{\text {MAA }}$ to $\left.t_{g x}\right)$ and the time post patent expiry

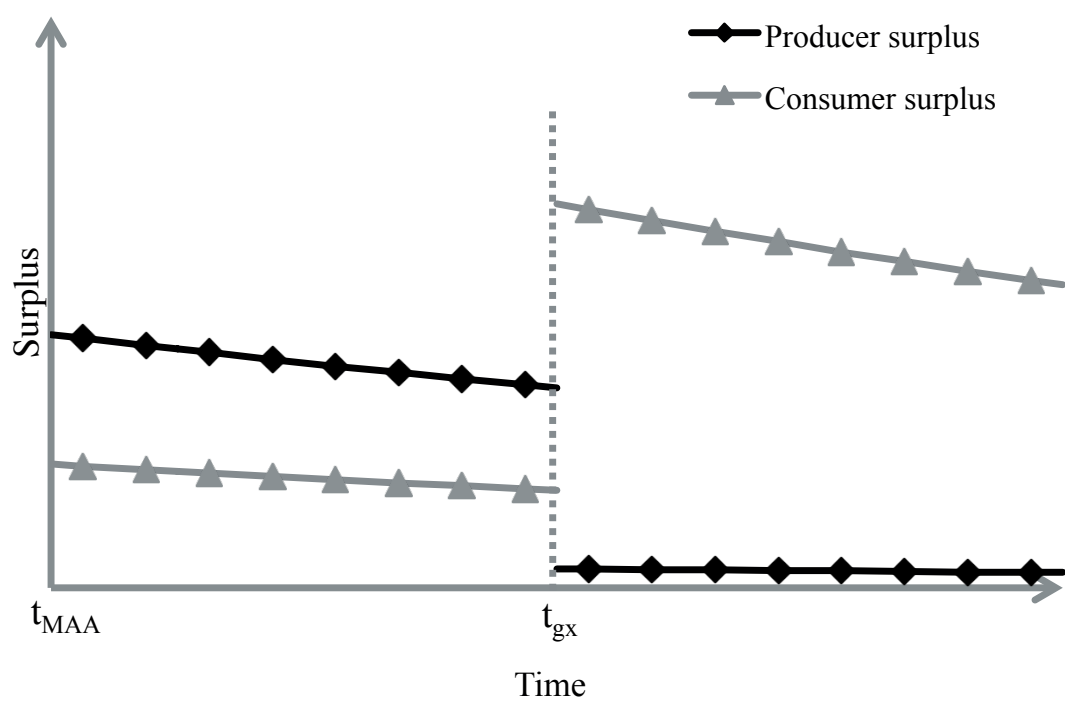

Note: Figure based on the numerical example outlined in Appendix 1. 
Table 1: Producer and consumer surplus during and post the end of market exclusivity.

\begin{tabular}{ccc}
\hline & During market exclusivity & Post patent expiry \\
\hline Producer surplus (PS) & $\sum_{t=t_{M A A}}^{t_{g x}} \frac{P S_{t}^{M}}{(1+r)^{t}}$ & $\sum_{t=t_{g x}}^{t_{\text {end }}} \frac{P S_{t}^{C}}{(1+r)^{t}}$ \\
\hline Consumer surplus (CS) & $\sum_{t=t_{M A A}}^{t_{g x}} \frac{C S_{t}^{M}}{(1+r)^{t}}$ & $\sum_{t=t_{g x}}^{t_{\text {end }}} \frac{C S_{t}^{C}}{(1+r)^{t}}$ \\
\hline Deadweight loss (DL) & $\sum_{t=t_{M A A}}^{t_{g x}} \frac{D L_{t}^{M}}{(1+r)^{t}}$ & 0 \\
\hline
\end{tabular}

where:

$\mathrm{r}$ is the discount rate

$P S_{t}^{M}$ is the producer surplus given monopoly pricing $\left(P_{t}^{M}\right)$ and quantity $\left(Q_{t}^{M}\right)$ in time period t:

$$
P S_{t}^{M}=\int_{0}^{Q_{t}^{M}}\left[P_{t}^{M}-M C_{t}\right] d Q
$$

$M C_{t}$ is the marginal cost (function) in time period $\mathrm{t}$

$P S_{t}^{C}$ is producer surplus under competitive pricing $\left(P_{t}^{C}\right)$ and quantity $\left(Q_{t}^{C}\right)$ in time period t:

$$
P S_{t}^{C}=\int_{0}^{Q_{t}^{C}}\left[P_{t}^{C}-M C_{t}\right] d Q
$$

$t_{\text {end }}$ is the time at which the technology loses relevance and utilisation

$C S_{t}^{M}$ is the consumer surplus given monopoly pricing and quantity in time period t:

$$
C S_{t}^{M}=\int_{0}^{Q_{t}^{M}}\left[D_{t}-P_{t}^{M}\right] d Q
$$

$D_{t}$ is the demand (function) in time period $\mathrm{t}$

$C S_{t}^{C}$ is consumer surplus under competitive pricing and quantity in time period t:

$$
C S_{t}^{C}=\int_{0}^{Q_{t}^{C}}\left[D_{t}-P_{t}^{C}\right] d Q
$$

$D L_{t}^{M}$ is the deadweight loss given monopoly pricing, which is equal to:

$$
D L_{t}^{M}=\int_{Q_{t}^{M}}^{Q_{t}^{C}}\left[D_{t}-M C_{t}\right] d Q
$$

\section{Analysis of demand side policies}

In this section, we analyse how demand side policies may impact expected rent and consumer surplus of pharmaceutical technologies during the time of patent protection and discuss the potential impact on R\&D incentives. The analysis focuses on policies subjected to recent debate in the Nordic countries; e.g. the reimbursement process, international reference pricing (IRP) and adoption into clinical practise (NRK, 2011; 
Persson et al., 2012; PIF, 2012; RIGSREVISIONEN, 2013; SKL, 2012; SOU 2012:75, 2012; Statsrevisorerne, 2011).

\subsection{Duration of market exclusivity}

Market exclusivity for sale of patented pharmaceuticals is the time from marketing authorisation approval ( $\left.t_{\mathrm{MAA}}\right)$ until time of patent expiry $\left(\mathrm{t}_{\mathrm{gx}}\right)$ which is determined by the European Medical Agency and patent law, respectively, in the EU. Decision to fund and implement a new technology in a given country or region may not be taken at $t_{\text {MAA }}$ thus reducing the duration of effective market exclusivity. When implementation decisions are delayed both expected rent and consumer surplus is reduced. The reduction is equal to the rent and surplus forgone when the technology is not utilised from $t_{\text {MAA }}$ until the time of implementation decision $\left(\mathrm{t}_{\tau}\right)$. Table 2 and Figure 3a,b demonstrates the impact of delayed implementation, with Figure $3 \mathrm{a}$ demonstrating the impact on expected rent and Figure $3 \mathrm{~b}$ the impact on consumer surplus. Note that Table 2 and Figure 3a,b also include the impact of pricing and adoption (analysed in sections 3.2-3.3).

Perhaps the most notable reason for increased time to an implementation decision, at least in the Nordic countries, is the health technology assessment (HTA) process associated with reimbursement decisions. Other processes such as national treatment guidelines and local treatment protocols may further influence the timing of implementation decisions. HTA and similar processes are used to assess the expected value, and thus net gain, of technologies. In essence HTA can be seen as a way to establish the appropriate quantity, i.e. patient population, given the price offered by the monopolist. The timing, duration and content of the HTA processes vary across countries. For example, the reimbursement process in Denmark can start at positive CHPM opinions with a maximum of 90 days duration. In contrast, Sweden has a maximum duration of 180 days and the process can be initiated after the time of EMA marketing authorisation approval (approximately 60 days after CHMP positive opinion).

Given that delayed implementation decisions reduce expected rent it may also reduce $R \& D$ incentives. However, it is important to note that this finding does not discourage the use of HTA or similar prioritisation policies. Formal assessments of healthcare technologies are an essential part of maximising health under a budget constraint and to reduce uncertainty in decision making (Claxton et al., 2002). Ensuring that technologies with a positive net gain are implemented (and utilised) is furthermore important for upholding R\&D incentives. This analysis rather illustrates the importance of taking into account not only the monetary but also the "time cost", i.e. forgone consumer surplus and expected rent, of operating HTA processes. It is unclear whether the different timing and length of appraisal processes across countries are due to different estimations of the cost and benefits of these processes, or a result of different political and governmental structures. 
Figure 3a: Illustration of demand side policies impact on expected rent

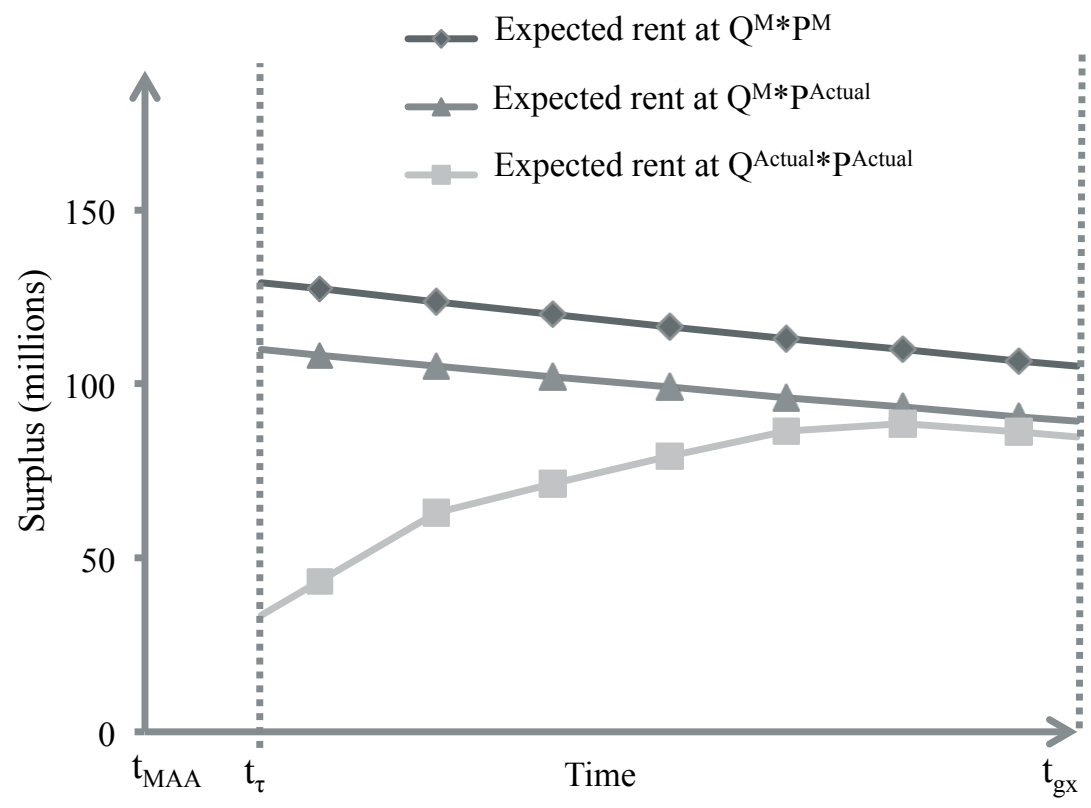

Figure 3b: Illustration of demand side policies impact on consumer surplus (CS)

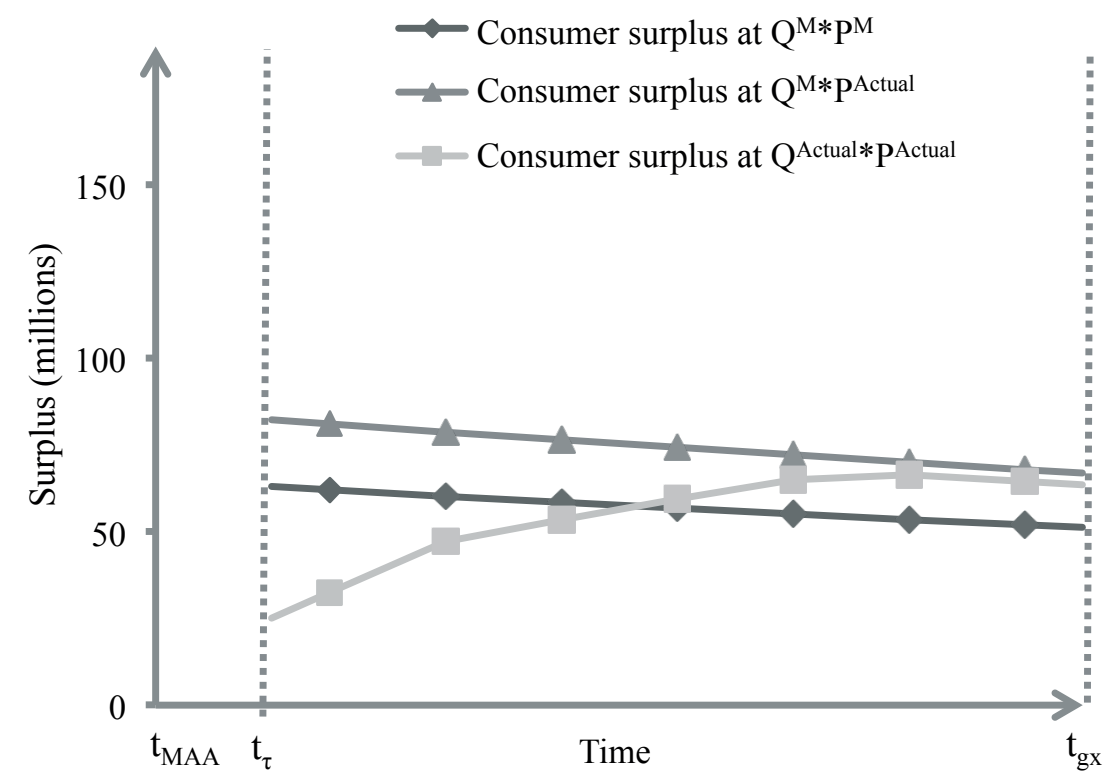

Notes: (a) illustrates expected rent and (b) consumer surplus, during the time of patent protection. The impact of: (i) postponed reimbursement decision at time $t_{\tau}$, (ii) price reduction through IRP or PT ( $\mathrm{P}^{\text {Actual }}<$ $\left.\mathrm{P}^{\mathrm{M}}\right)$, and (iii) lower adaptation into clinical practice $\left(\mathrm{Q}^{\mathrm{Actual}}<\mathrm{Q}^{\mathrm{M}}\right)$ are demonstrated. The figures are based on the numerical example in Appendix 1. 
Table 2: Illustration of demand side policies impact on expected rent and consumer surplus

\begin{tabular}{lll}
\hline & Expected rent & Consumer surplus \\
\hline $\begin{array}{l}\text { Reduced time of "market exclusivity" } \\
\left.\text { (implementation at time } \mathrm{t}_{\tau} \text { instead of } \mathrm{t}_{\mathrm{MAA}}\right)\end{array}$ & $\downarrow$ & $\downarrow$ \\
\hline $\begin{array}{l}\text { Price reduction due to due to IRP or PT } \\
\left(\mathrm{P}^{\text {Actual }}<\mathrm{P}^{\mathrm{M}}\right)\end{array}$ & $\downarrow$ & $\uparrow / 0^{5}$ \\
\hline $\begin{array}{l}\text { Lower than } \mathrm{Q}^{\mathrm{M}} \text { adaptation into clinical practice } \\
\left(\mathrm{Q}^{\text {Actual }}<\mathrm{Q}^{\mathrm{M}}\right)\end{array}$ & $\downarrow$ & $\downarrow$ \\
\hline $\begin{array}{l}\text { Generic substitution } \\
\text { (post the time of patent expiry) }\end{array}$ & 0 & 0 \\
\hline
\end{tabular}

Note: The arrows in the table demonstrate the expected rent and consumer surplus impact of the demand side policies that is analysed in section 3.1-3.4; where $\uparrow, \downarrow$ and 0 indicate an increase, decrease and no impact, respectively. The mathematical foundation for the rent and surplus impacts are presented in Appendix 2.

\subsection{Price setting}

The widespread use of price regulation in the form of international reference pricing (IRP) and the occurrence of parallel trade (PT) prevent producers to set and sell at profit maximizing prices. With the occurrence of IRP or parallel import, the actual price of pharmaceuticals will be:

I) $P_{t}^{\text {Actual }}=\alpha_{t} * P_{t}^{P T}+\left(1-\alpha_{t}\right) *\left(\beta_{t} * P_{t}^{I R P}+\left(1-\beta_{t}\right) * P_{t}^{M}\right)$

where:

$\alpha_{t}$ is the proportion of sold products that are parallel imported in time period $\mathrm{t}$

$P_{t}^{P T}$ is the price paid to the producer for the parallel imported products (in the market where it is purchased) in time period $t$

$\beta_{t}$ is a binary variable indicating if a product is priced through IRP in time period $\mathrm{t}$

$P_{t}^{I R P}$ is the price based on international referencing in time period $\mathrm{t}$

When IRP or PT reduce the price below $\mathrm{P}^{\mathrm{M}}\left(P_{t}^{I R P}<P_{t}^{M}\right.$ or $\left.P_{t}^{P T}<P_{t}^{M}\right)$ expected rent is reduced and consumer surplus increases, as demonstrated in Table 2 and Figure 3a,b. If price is reduced without impacting quantity $\left(\mathrm{Q}^{\mathrm{M}}\right)$ the gain in consumer surplus is equal to the reduction in expected rent, and IRP or PT simply lead to a surplus transfer from producers to consumers.

\footnotetext{
${ }^{5}$ There is an increase in consumer surplus when price is lowered by IRP or PT. However, the design of the specific PT or IRP policies determines if that surplus will be attained by consumers, i.e. patients or payers, or rather parallel trades and pharmacies, as is outlined in section 3.2.
} 
When IRP and PT reduce the price below $\mathrm{P}^{\mathrm{M}}$, it could reduce the deadweight loss of monopoly pricing by increasing quantity (i.e. locating on a lower point on the demand curve). The increase in consumer surplus from operating on a lower point on the demand curve would be larger than the reduction in expected rent and hence imply a potential Pareto improvement. Nevertheless, unless producers are compensated for operating on a lower point on the demand curve expected rent is reduced.

The analysis demonstrates that the increase in consumer surplus from utilising IRP and PT comes at the expense of lover expected rent and thereby lower R\&D incentives, unless the producers are compensated. Assuming that lower R\&D incentives leads to lower R\&D investment, IRP and PT will result in fewer technologies developed in the future. Therefore, IRP and PT essentially increase consumer surplus today at the expense of lower future consumer surplus.

It should be noted that the increase in consumer surplus might partially, or fully, be attained by parties such as parallel traders or pharmacies and may therefore not (at least directly) benefit the end consumer or payer (Danzon, 1997; Kanavos and Costa-Font, 2005). The distribution of the gained consumer surplus depends on the policy design, as is clearly exemplified in a recent report by the Dental and Pharmaceutical Benefits Board (TLV) in Sweden. The report estimates that pharmacies earned around 1 billion SEK in 2012 from the sale of parallel traded products and that this did not result in any price reduction to patients or the regional payers (TLV, 2014).

The practise of IRP, applied in both Norway and Finland as well as in most other European countries, contrasts value based pricing (VBP). Under VBP, which is claimed to be operated in Sweden ${ }^{6}$ (Persson, 2012; Persson et al., 2012), a pharmaceutical technology would be priced based on the value it provides. A value based price (and quantity combination) can thus be defined as a price (and quantity combination) that lies on or below the demand curve. Given that demand may vary across countries, for example due to different treatment patterns and willingness/ability to pay, value based prices may also be different across countries. Thus VBP is consistent with differential pricing (across countries), which has been argued to lead to economic efficiency (Danzon and Towse, 2003; Danzon et al., 2015). In contrast IRP limits the potential for price differentiation and may lead to dynamic inefficiency.

It may be argued that the use of IRP and PT in small markets, like the Nordic countries, have no or only marginal impact on global expected rent and therefore also no or marginal impact on R\&D incentives. This notion is explored further in section 4 .

\subsection{Adoption into clinical practise}

In the Nordic countries, reimbursement decisions to fund a technology are often taken at a national level whereas decisions to adopt a technology into clinical practice are often taken at a local level (e.g. county council or hospital). If pharmaceuticals are only utilised in a subset $\left(\mathrm{Q}^{\text {Actual }}\right)$ of the full patient population for which it is expected to constitute a net gain $\left(\mathrm{Q}^{\mathrm{M}}\right)$ it will reduce both expected rent and consumer surplus, as demonstrated in table 2 and Figure 3a,b. The impact from lower than $\mathrm{Q}^{\mathrm{M}}$ adoption is the rent and surplus forgone for those individuals who are not treated. The rent and surplus impact from low adoption depends on two factors: (i) lower than $\mathrm{Q}^{\mathrm{M}}$ adoption, implying that the technology is not fully implemented in all patients where it constitutes a net gain; (ii) the time it takes to

\footnotetext{
${ }^{6}$ Given the lack of a clearly stated cost-effectiveness threshold or willingness to pay as well as lack of transparency on how for example severity impacts the willingness to pay, it can be argued that the Swedish price setting might not be truly value based. The increasing focus on price negotiations as a part of price setting (TLV, 2015) further questions the merits of VBP in Sweden.
} 
reach maximum adoption level, for example due to sequential adoption across patient populations or regions.

Consumer surplus may vary between individuals given variation in treatment effects. Thus, the loss in consumer surplus may depend on the characteristics of the individuals or patient groups that are not treated. Societies therefore have stronger incentive to adopt a technology for individuals or patient groups for whom it provides a higher value, and lower incentive to utilise the technology for individuals or patient groups where the value is lower. In contrast, the rent reduction is independent of which patients that do not get treatment. Unless producers expect technologies to be fully adopted into clinical practise and thus utilised for all individuals, for whom they are estimated to constitute a net gain, incentives to invest in R\&D are reduced.

Assuming that funding for new technologies comes from disinvestments in currently utilised (and patented) technologies the reduction in expected rent due to later implementation may partially (or fully) benefit these currently utilised technologies. In this way it could be argued that later implementation would be a zero sum game for rent across new and currently utilised technologies. However, the allocation of rent between these technologies is important for R\&D incentives, since it is the expected rent on new technologies that drive R\&D incentives.

The Swedish healthcare system is an example of a decentralized healthcare system where implementation decisions are taken at different levels (national, regional and local). These "layers" may influence implementation decisions, and it has been demonstrated that this can lead to unequal (lower or later) implementation of technologies across regions (Persson et al., 2012; SWEDEHEART, 2014).

\subsection{Generic substitution}

After patent expiry generic competition is expected to enter the market. This is expected to drive down the price and will therefore increase consumer surplus. The increase in consumer surplus is the result of reducing (or eliminating) the deadweight loss of monopoly pricing as well as a shift from producer to consumer surplus. Many countries, including the Nordic, have implemented generic substitution policies to bring down prices post patent expiry in order to facilitate a shift towards increased consumer surplus (Vogler, 2012).

Assuming that generic substitution does not occur until patents expire, expected rent remains unaffected as it is defined as producer surplus during the time of patent protection. Hence, generic substitution policies should not impact R\&D incentives as developers cannot expect to earn rent post patent expiry. However, generic substitution may influence expected rent and R\&D incentives through PT and IRP, since patents do not expire simultaneously across countries, and IRP or PT may thus reduce the price in countries where patent protection is still in effect. This is, nevertheless, no good argument against generic substitution, which plays an important role in maximising the value of pharmaceuticals to societies. This rather demonstrates how IRP and PT policies may reduce the expected rent in countries where technologies are still patented.

\subsection{Combined effect}

Based on the analysis presented in this section we can update the mathematical expression of expected rent to include the impact of different demand side policies: 
II) $\sum_{t=t_{\tau}}^{t_{g x}} \frac{P S_{t}^{\text {Actual }}}{(1+r)^{t}}$

where:

$P S_{t}^{\text {Actual }}$ is the producer surplus given actual price $\left(P_{t}^{\text {Actual }}\right)$ and quantity $\left(Q_{t}^{\text {Actual }}\right)$ in time period t:

$$
P S_{t}^{\text {Actual }}=\int_{0}^{Q_{t}^{\text {Actual }}}\left[P_{t}^{\text {Actual }}-M C_{t}\right] d Q
$$

\section{Global context}

Until now, the framework and analysis have focused on a single pharmaceutical market, i.e. a given country or region. To evaluate the impact of pharmaceutical demand side policies on total expected rent across countries we define "global rent" as the sum of expected rent across markets. Based on the analysis in the previous section global rent can be writes as:

III) $\sum_{n=1}^{N} \sum_{t=t_{\tau, n}}^{t_{g x, n}} \frac{P S_{t, n}^{\text {Actual }}}{(1+r)^{t}}$

where:

$P S_{t, n}^{A c t u a l}$ is the producer surplus given actual price $\left(P_{t, n}^{\text {Actual }}\right)$ and quantity $\left(Q_{t, n}^{\text {Actual }}\right)$ in time period $\mathrm{t}$ in market $\mathrm{n}$ :

$$
P S_{t, n}^{\text {Actual }}=\int_{0}^{Q_{t, n}^{\text {Actual }}}\left[P_{t, n}^{\text {Actual }}-M C_{t, n}\right] d Q
$$

with $\mathrm{P}_{\mathrm{t}, \mathrm{n}}^{\text {Actual }}$ defined as:

$$
P_{t, n}^{A c t u a l}=\alpha_{t, n} * P_{t, n}^{P T}+\left(1-\alpha_{t, n}\right) *\left(\beta_{t, n} * P_{t, n}^{I R P}+\left(1-\beta_{t, n}\right) * P_{t, n}^{M}\right)
$$

$\alpha_{t, n}$ is the proportion of sold products that are parallel imported into market $\mathrm{n}$ in time period $\mathrm{t}$

$P_{t, n}^{P T}$ is the price paid to the producer for the products that are parallel imported to market $\mathrm{n}$ (in the market where it is purchased) in time period $\mathrm{t}$

$\beta_{t, n}$ is a binary variable indicating if a product is priced through IRP in time period $\mathrm{t}$ in market $\mathrm{n}$

$P_{t, n}^{I R P}$ is the price based on international referencing in time period $\mathrm{t}$ in market $\mathrm{n}$ 


\subsection{Global impact of single market price reduction}

A price reduction in large pharmaceutical markets, like the US, could have a large impact on global rent given the magnitude of rent contribution from large markets. However, most markets, like the Nordic countries (EFPIA, 2013), constitute a small fraction of the total pharmaceutical market whereby a reduction in price, and rent, is likely to have marginal impact on global rent. However, the use of IRP and PT leads to potential spillover effects from single market price reductions.

If a price reduction occurs in a country with significant parallel export, or significantly increases parallel export, rent is also reduced in market(s) importing from the price reducing country. Furthermore, the use of IRP leads to price spill-over, since the price in countries utilising IRP essentially is a function of prices in other countries as outline in equation IV.

IV) $P_{t, n}^{I R P}=\sum_{s=1}^{S} P_{t, s} * w_{t, n, s}$

where:

$\mathrm{S}$ is the total number of countries where the technology has a price that can be referenced

$\mathrm{P}_{\mathrm{t}, \mathrm{s}}$ is the price in the referenced country $\mathrm{s}$ in time period $\mathrm{t}$

$\mathrm{W}_{\mathrm{t}, \mathrm{n}, \mathrm{s}}$ is the weight of country s's price $\left(\mathrm{P}_{\mathrm{t}, \mathrm{s}}\right)$ in country n's price equation in time period $\mathrm{t}$

Reductions of prices that are referenced by other countries will spill-over to these referencing countries. The magnitude of the spill-over depends on several factors including the number and size of countries referencing the given county's price and the weight this price have in other countries price setting.

Countries referenced by many or large markets are likely to have higher spill-over from price reductions compared to markets referenced by few or small markets. The wide spread use of IRP and PT increases the likelihood of spill-over and non-marginal global rent impact from price reductions (Kanavos and Costa-Font, 2005; Kanavos et al., 2010; Leopold et al., 2012). The Nordic countries are referenced by many and large markets (Leopold et al., 2012), whereby price reductions for example in Denmark and Sweden may have non-marginal impact on global rent, even though Denmark and Sweden are not themselves using IRP.

It has been described how producers may try to reduce the potential spill-over effect to higher priced markets by setting higher prices and delaying availability in the lower priced markets (Kanavos et al., 2010; World Health Organization, 2013). Delaying availability and increasing prices above $\mathrm{P}^{\mathrm{M}}$ will reduce rent as well as consumer surplus in these markets. The gains to markets utilising IRP therefore come partially at the expense of other (primarily poorer) countries that get access to technologies later, or not at all, and possibly at a higher price (Danzon et al., 2005; Kanavos et al., 2010; World Health Organization, 2013). 


\section{Discussion}

The framework and analyses outlined in this paper demonstrate how demand side policies may influence the value of pharmaceutical technologies to consumers, i.e. consumer surplus, as well as how these policies impact rent and thus R\&D incentives. Our work illustrates the importance of long-term policy analysis to ensure that policies controlling price and utilisation do not achieve short-term optimisation (i.e. static efficiency) at the expense of long-term optimisation (i.e. dynamic efficiency). By providing a framework for policy analysis this work could offer a starting point for discussions and analysis of these thorny policy questions.

The analyses show how postponed reimbursement of technologies with a positive net gain will have a negative impact on both consumer surplus and expected rent. It is, however, important to stress that we are not suggesting that all pharmaceuticals should be implemented immediately without any evaluation or assessment. In fact we would argue the opposite. A balanced assessment of costs and benefits of HTA designs is needed to ensure that appraisal processes constitute a net gain for both short and long-term population health.

Our results suggest that international reference pricing and parallel trade influence R\&D incentives, although further research is needed to quantify this impact. By reducing R\&D incentives these policies may reduce the number of new technologies being developed and might thus have a negative impact on future consumer surplus and population health. Consequently, our analyses pose some questions around the implications and distributive effects of these price-focused policies; especially since pharmacies and parallel trades may capture the majority of any additional consumer surplus.

Adoption into clinical practise influences consumer surplus and expected rent, as was demonstrated in our analysis. This includes the often applied sequential implementation approach (providing a technology to a subgroup of patients first in order to gain experience with the new technology) as well as the situation where a technology is never fully implemented for all patients to whom it is expected to provide a net gain. In the latter case it is relatively clear that surplus is reduced, whereas the former may warrant further assessment of cost and benefit of a sequential introduction, an exercise that rarely takes place (explicitly) today.

Uncertainty around treatment effect and whether a technology constitutes a net gain may be one reason for societies to delay implementation decisions and utilise sequential implementation of new technologies. The benefits of handling uncertainty in this way must, however, be weighed against the cost of reduced consumer surplus and expected rent. Uncertainty should further be reflected in the demand (curve) for a technology, i.e. lower demand when uncertainty around benefit or cost-effectiveness is high. It therefore seems attractive to handle uncertainty in the (centralised) reimbursement decision rather than handling it (differently) in local decision on sequential implementation.

This work is based on the key assumption that R\&D incentives are influenced by expected rent. Rent is not the same as profit and it might be argued that rent impacts could be insignificant for R\&D incentives given the relatively high profit margins of the pharmaceutical sector. However, it does seem reasonable that reducing the reward, i.e. rent, for those technologies that are successful through the development process will reduce incentives to invest in the R\&D of new technologies. Several empirical studies have demonstrated the link between rent and R\&D investments supporting the framework outlined in this work (Grabowski and Vernon, 2000; Malmberg, 2008; Vernon, 2005). 
Further empirical studies are encouraged to validate the findings and the policy conclusions drawn from our study, and the theoretical model could perhaps be a vehicle for such studies.

In conclusion we believe that a structured way of analysing the complex and interlinked policy questions addressed in this work can lead to more transparency in healthcare decision making as well as a better understanding of the trade-offs between maximising the value of currently available technologies and incentivising future technological development. Importantly, the purpose of this paper is not to be prescriptive in terms of what policies should be utilised, and how. Rather, the aim has been to provide a framework for a coherent long-term policy analysis to ensure that policies aimed at getting value today, from our limited healthcare resources, do not do so at the expense of undermining R\&D incentives, ultimately with implications for long-term health.

\section{Conflicts of interest}

The authors are both employed at AstraZeneca. However, the opinions in this paper reflect those of the authors and not necessarily those of AstraZeneca.

\section{References}

Agitha, T. G. (2013). Alternative incentive models delinking R \& D costs from pharmaceutical product price. Journal of Intellectual Property Rights, 18(September), 491-498.

Appleby, J. (2013). Spending on health and social care over the next 50 years Why think long term? (F. Weston, Ed.). London: The King's Fund.

Carlton, D. W., and Perloff, J. M. (2005). Patents and technological change. Modern Industrial Organization (Fourth.). USA: Pearson Addison Wesley.

Civan, A., and Maloney, M. T. (2006). Contributions to economic analysis \& policy the determinants of pharmaceutical research and development investments the determinants of pharmaceutical research and development investments. Contributions to Economic Analysis \& Policy, 5(1), Article 28.

Claxton, K. (2007). OFT , VBP: QED ? Health Economics, 558, 545-558.

Claxton, K. P., Walker, S., Palmer, S. J., and Sculpher, M. J. (2010). Appropriate perspectives for health care decisions. CHE Research Paper 54, York.

Claxton, K., Sculpher, M., and Drummond, M. (2002). Viewpoint A rational framework for decision making by the National Institute for Clinical Excellence ( NICE ). The Lancet, 360, $711-715$.

Danzon, P. M. (1997). Price discrimination for pharmaceuticals: Welfare effects in the US and the EU. International Journal of the Economics of Business, 4(3), 301-322.

Danzon, P. M., and Towse, A. (2003). Differential pricing for pharmaceuticals: Reconciling access, R\&D and patents. International Journal of Health Care Finance and Economics, 3(3), $183-205$.

Danzon, P. M., and Towse, A. (2005). Theory and implementation of differential pricing for pharmaceuticals. In K. E. Maskus and J. H. Reichman (Eds.), International Public Goods and Transfer of Technology Under a Globalized Interllectual Property Regime (First., pp. 425456). Cambridge: Cambridge University Press.

Danzon, P. M., Wang, Y. R., and Wang, L. (2005). The impact of price regulation on the launch delay of new drugs - evidence from twenty-five major markets in the 1990s. Health Economics, 14(3), 269-92. 
Danzon, P., Towse, A., and Mestre-Ferrandiz, J. (2015). Value-based differential pricing: Efficient prices for drugs in a global context. Health Economics. 24(3), 294-301.

Dimasi, J. A., and Grabowski, H. G. (2004). Patents and R\&D Incentives: Comments on the Hubbard and Love trade framework for financing pharmaceutical R\&D. Retrieved May 30, 2014, from http://cdrwww.who.int/intellectualproperty/news/en/Submission3.pdf

EFPIA. (2013). The pharmaceutical industry in figures - key data 2013. Retrieved May 31, 2014, from www.efpia.eu/uploads/Figures_Key_Data_2013.pdf

Grabowski, H. (2005). Increasing R\&D incentives for neglected diseases: Lesson from the Orphan Drugs ACT. In K. E. Maskus and J. H. Reichman (Eds.), International Public Goods and Transfer of Technology Under a Globalized Interllectual Property Regime (First., pp. 457480). Cambridge: Cambridge University Press.

Grabowski, H., and Vernon, J. (2000). The determinants of pharmaceutical research and development expenditures. Journal of Evolutionary Economics, 10(1-2), 201-215.

Grootendorst, P. V, and Edwards, A. (2014). Patents and other incentives for pharmaceutical innovation. In A. J. Culyer (Ed.), Encyclopedia of Health Economics (Vol. 2, pp. 434-442). Elsevier Ltd.

Hubbard, T., and Love, J. (2004). A new trade framework for global healthcare R\&D. PLoS Biology, 2(2), E52.

Kanavos, P. (2003). Overview of pharmaceutical pricing and reimbursement regulation in Europe. Japanese Pharmacology and Therapeutics, 30(10), 819-838.

Kanavos, P., and Costa-Font, J. (2005). Pharmaceutical parallel trade in Europe: Stakeholder and competition effects. Economic Policy, (October), 751-798.

Kanavos, P., Nicod, E., Espin, J., and Den, S. Van. (2010). Short- and long-term effects of valuebased pricing $v$ s . external price referencing. EMIN€T.

Kaul, I., Grunberg, I., and Stern, M. (1999). Conclusion. In I. Kaul, I. Grungberg, and M. Stern (Eds.), Global public goods: international cooperation in the 21st century (pp. 450-508). New York: Oxford University Press.

Kaul, I., and Mendoza, R. U. (2003). Advancing the concept of public goods. In I. Kaul, P. Conceicai, K. Le Goulven, and R. U. Mendoza (Eds.), Providing Global Public Goods: Managing Globalization (First., pp. 78-112). Cary, NC: Oxford University Press.

Leopold, C., Vogler, S., Mantel-Teeuwisse, A. K., de Joncheere, K., Leufkens, H. G. M., and Laing, R. (2012). Differences in external price referencing in Europe - A descriptive overview. Health Policy, 104, 50-60.

Lichtenberg, F., and Pettersson, B. (2014). Economics of innovation and new technology the impact of pharmaceutical innovation on longevity and medical expenditure in Sweden, 1997 2010: Evidence from longitudinal, disease- level data. Economics of Innovation and New Technology, 23(3), 239-273.

Lichtenberg, F. R. (2004). Sources of U.S. longevity increase, 1960-2001. The Quarterly Review of Economics and Finance, 44(3), 369-389.

LIF. (2014). Fakta 2014 - Läkemedelsmarknaden och hälso- och sjukvården Swedish Pharmaceutical Market and Health Care. Stockholm, Sweden: LIF.

Malmberg, C. (2008). Paper no. 2008/01 $R \& D$ and financial systems: the determinants of $R \&$ Dexpenditures in the Swedish pharmaceutical industry. Centre for Innovation, Research and Competence in the Learning Economy (CIRCLE) Lund University, Lund.

Mestre-ferrandiz, J., Sussex, J., and Towse, A. (2012). The R\&D cost of a new medicine. London: Office of Health Economics.

Moon, S. (2008). Medicines as global public goods: The governance of technological innovation in the new era of global health. Global Health Governance, $I I(2)$. 
Munos, B. (2009). Lessons from 60 years of pharmaceutical innovation. Nature reviews. Drug Discovery, 8(12), 959-68.

NRK. (2011). Norge har mange av Skandinavias dyreste kopimedisiner. Brennpunkt. Retrieved May 30, 2014, from www.nrk.no/programmer/tv/brennpunkt/1.7537799

OECD. (2013). Health at a glance 2013: OECD Indicators. OECD

Persson, U. (2012). Value based pricing in sweden: Lessons for design? OHE seminar briefing, $12,1-11$.

Persson, U., Svensson, J., and Pettersson, B. (2012). A new reimbursement system for innovative pharmaceuticals combining value-based and free market pricing. Applied Health Economics and Health Policy, 10(4), 217-225.

PIF. (2012). Medicines reimbursement system revision is indispensible. Situation report 2-2012. Retrieved May 30, 2014, from www.pif.fi/frontpage/media/situation_report/sitrep_22012/ medicines_reimbursement_system_revision

Rigsrevisionen. (2013). Notat til Statsrevisorerne om beretning om indkøb af sygehusmedicin April. Copenhagen: Rigsrevisionen.

Sandler, T. (1999). Intergenerational public goods: Strategies, Efficiency and Institutions. In I. Kaul, I. Grungberg, and M. Stern (Eds.), Global public goods (First., pp. 20-50). New York: Oxford university press.

SKL. (2012). Ordnat införande i samverkan Slutrapport från nationella läkemedelsstrategin, delprojekt 6.1. Stockholm: Sveriges Kommuner och Landsting.

SOU 2012:75. (2012). Pris, tillgång och service - fortsatt utveckling av läkemedels- och apoteksmarknaden. Stockholm: Socialdepartementet.

Statsrevisorerne. (2011). Beretning nr. 13 Beretning om indkøb af sygehusmedicin Beretning om indkøb af sygehusmedicin. Copenhagen: Rosendahls-Schultz Distribution.

SWEDEHEART. (2014). SWEDEHEART Annual report 2013. Uppsala: SWEDEHEART.

TLV. (2014). Apoteksmarknadens bruttoresultat 2012 - en analys av parallellimportens betydelse. Stockholm: Tandvårds- och läkemedelsförmånsverket.

TLV. (2015). Utvecklad värdebaserad prissättning - regeringsuppdrag (dnr S2014/8964/FS). Stockholm: Tandvårds- och läkemedelsförmånsverket.

Vernon, J. a. (2005). Examining the link between price regulation and pharmaceutical R\&D investment. Health Economics, 14(1), 1-16.

Vogler, S. (2012). The impact of pharmaceutical pricing and reimbursement policies on generics uptake: implementation of policy options on generics in 29 European countries-an overview. Generics and Biosimilars Initiative Journal, 1(2), 93-100.

Vogler, S., Zimmermann, N., Leopold, C., and de Joncheere, K. (2011). Pharmaceutical policies in European countries in response to the global financial crisis. Southern med review, 4(2), 6979.

World Health Organization. (2013). WHO Guideline on Country Pharmaceutical Pricing Policies. Geneva: World Health Organization. 


\section{Appendix 1: Details of the numerical example used to create Figure 1-3}

Demand: $\mathrm{D}_{\mathrm{t}}=40.000-2,5 \mathrm{Q}$

Marginal cost: $\mathrm{MC}_{\mathrm{t}}=500+0,05 \mathrm{Q}$

Monopoly price: $P_{t}^{M}=20.446$

Monopoly quantity: $Q_{t}^{M}=7.822$

Competitive price: $P_{t}^{C}=1.275$

Competitive quantity: $Q_{t}^{c}=15.490$

Discount rate: $3 \%$

Time of marketing authorisation approval $\left(\mathrm{t}_{\mathrm{MAA}}\right)$ is at the start of time period 1

Time of patent expiry $\left(\mathrm{t}_{\mathrm{gx}}\right)$ is at the end of time period 8

Time that the technology looses relevance $\left(t_{\text {end }}\right)$ is at the end of time period 16

Time of implementation decision $\left(\mathrm{t}_{\tau}\right)$ is at the start of time period 2

Price due to the use of IRP and PT: $P_{t}^{\text {Actual }}=0,85^{*} P_{t}^{M}$

Adoption into clinical practice $\left(Q_{t}^{\text {Actual }}\right): Q_{2}^{\text {Actual }}=0,40 * Q_{t}^{M}, Q_{3}^{\text {Actual }}=0,60 * Q_{t}^{M}, Q_{4}^{\text {Actual }}=$ $0,70 * Q_{t}^{M}, Q_{5}^{\text {Actual }}=0,80 * Q_{t}^{M}, Q_{6}^{\text {Actual }}=0,90 * Q_{t}^{M}, Q_{7}^{\text {Actual }}=0,95 * Q_{t}^{M}, Q_{8}^{\text {Actual }}=0,95 * Q_{t}^{M}$

Appendix 2: Tables outlining the mathematical representation of expected rent and consumer surplus given the impact of demand side policies outlined in section 3

Table A1: Expected rent and consumer surplus during the time of patent protection given postponed implementation decision at time $\mathbf{t}_{\tau}$

\begin{tabular}{lcc}
\hline Expected rent & $\sum_{t=t_{\tau}}^{t_{g x}} \frac{P S_{t}^{M}}{(1+r)^{t}}$ & $-\sum_{t=t_{M A A}}^{t_{\tau}} \frac{P S_{t}^{M}}{(1+r)^{t}}$ \\
\hline Consumer surplus & $\sum_{t=t_{\tau}}^{t_{g x}} \frac{C S_{t}^{M}}{(1+r)^{t}}$ & $-\sum_{t=t_{M A A}}^{t_{\tau}} \frac{C S_{t}^{M}}{(1+r)^{t}}$ \\
\hline
\end{tabular}


Table A2: Expected rent and consumer surplus during the time of patent protection given the use of IRP or PT and unchanged utilisation $\left(Q^{\mathrm{M}}\right)$.

During market exclusivity

Difference compared to monopolistic rent and surplus given $\mathrm{Q}^{\mathrm{M}}$

\begin{tabular}{|c|c|c|}
\hline Expected rent & $\sum_{t=t_{M A A}}^{t_{g x}} \frac{P S_{t}^{P_{t}^{\text {Actual }}}}{(1+r)^{t}}$ & $-\sum_{t=t_{M A A}}^{t_{g x}} \frac{\left(P_{t}^{M}-P_{t}^{\text {Actual }}\right) * Q_{t}^{M}}{(1+r)^{t}}$ \\
\hline Consumer surplus & $\sum_{t=t_{M A A}}^{t_{g x}} \frac{C S_{t}^{P_{t}^{\text {Actual }}}}{(1+r)^{t}}$ & $\sum_{t=t_{M A A}}^{t_{g x}} \frac{\left(P_{t}^{M}-P_{t}^{\text {Actual }}\right) * Q_{t}^{M}}{(1+r)^{t}}$ \\
\hline
\end{tabular}

where:

$P S_{t}^{P_{t}^{A c t u a l}}$ is producer surplus given $P_{t}^{\text {Actual }}$ in time period t: $P S_{t}^{P_{t}^{\text {Actual }}}=\int_{0}^{Q_{t}^{M}}\left[P_{t}^{\text {Actual }}-M C_{t}\right] d Q$

$C S_{t}^{P_{t}^{\text {Actual }}}$ is consumer surplus given $P_{t}^{\text {Actual }}$ in time period t: $C S_{t}^{P_{t}^{\text {Actual }}}=\int_{0}^{Q_{t}^{M}}\left[D_{t}-P_{t}^{\text {Actual }}\right] d Q$

Table A3: Expected rent and consumer surplus during the time of patent protection given the use of IRP or PT and increased utilisation at price $\mathbf{P}^{\text {Actual }}\left(\mathbf{Q}^{\mathbf{P}^{\text {Actual }}}>\mathbf{Q}^{\mathrm{M}}\right)$

\begin{tabular}{|c|c|c|}
\hline & $\begin{array}{l}\text { Rent \& surplus during } \\
\text { patent protection }\end{array}$ & $\begin{array}{l}\text { Rent and surplus difference compared to } \\
\text { monopolistic rent and surplus given } \mathrm{Q}^{\mathrm{M}}\end{array}$ \\
\hline Expected rent & $\sum_{t=t_{M A A}}^{t_{g x}} \frac{P S_{t}^{Q_{t}^{P^{A c t u a l}}}}{(1+r)^{t}}$ & $-\sum_{t=t_{M A A}}^{t_{g x}} \frac{P S_{t}^{M}-P S_{t}^{Q_{t}^{P^{A c t u a l}}}}{(1+r)^{t}}$ \\
\hline Consumer surplus & $\sum_{t=t_{M A A}}^{t_{g x}} \frac{C S_{t}^{Q_{t}^{P^{A c t u a l}}}}{(1+r)^{t}}$ & $\sum_{t=t_{M A A}}^{t_{g x}} \frac{C S_{t}^{M}-C S_{t}^{Q_{t}^{\text {Actual }}}}{(1+r)^{t}}$ \\
\hline
\end{tabular}

where

$P S_{t}^{Q_{t}^{P}}{ }^{\text {Actual }}$ is producer surplus given $P_{t}^{\text {Actual }}$ and $Q_{t}^{P^{A c t u a l}}$ in time period t:

$$
P S_{t}^{Q_{t}^{P^{A c t u a l}}}=\int_{0}^{Q_{t}^{P^{\text {Actual }}}}\left[P_{t}^{\text {Actual }}-M C_{t}\right] d Q
$$

$C S_{t}^{P_{t}^{A c t u a l}}$ is consumer surplus given $P_{t}^{\text {Actual }}$ and $Q_{t}^{P^{\text {Actual }}}$ in time period t:

$$
C S_{t}^{Q_{t}^{P^{A c t u a l}}}=\int_{0}^{Q_{t}^{P^{A c t u a l}}}\left[D_{t}-P_{t}^{\text {Actual }}\right] d Q
$$


Table A4: Expected rent and consumer surplus during the time of patent protection given lower than $\mathbf{Q}^{\mathrm{M}}$ adoption

\begin{tabular}{lcc}
\hline & During market exclusivity & $\begin{array}{c}\text { Difference compared to monopolistic } \\
\text { rent and surplus given } \mathrm{Q}^{\mathrm{M}}\end{array}$ \\
\hline Expected rent & $\sum_{t=t_{M A A}}^{t_{g x}} \frac{P S_{t}^{Q_{t}^{A c t u a l}}}{(1+r)^{t}}$ & $-\sum_{t=t_{M A A}}^{t_{g x}} \frac{P S_{t}^{M}-P S_{t}^{Q_{t}^{A c t u a l}}}{(1+r)^{t}}$ \\
\hline Consumer surplus & $\sum_{t=t_{M A A}}^{t_{g x}} \frac{C S_{t}^{Q_{t}^{A c t u a l}}}{(1+r)^{t}}$ & $-\sum_{t=t_{M A A}}^{t_{g x}} \frac{C S_{t}^{M}-C S_{t}^{Q_{t}^{A c t u a l}}}{(1+r)^{t}}$ \\
\hline
\end{tabular}

where:

$P S_{t}^{Q_{t}^{\text {Actual }}}$ is producer surplus given $Q_{t}^{\text {Actual }}$ in time period t: $P S_{t}^{Q_{t}^{\text {Actual }}}=\int_{0}^{Q_{t}^{\text {Actual }}}\left[P_{t}^{M}-M C_{t}\right] d Q$

$Q_{t}^{\text {Actual }}$ is the quantity utilised in time period $\mathrm{t}$

$C S_{t}^{Q_{t}^{\text {Actual }}}$ is consumer surplus given $Q_{t}^{\text {Actual }}$ in time period t: $C S_{t}^{Q_{t}^{\text {Actual }}}=\int_{0}^{Q_{t}^{\text {Actual }}}\left[U_{t}-P_{t}^{M}\right] d Q$

$U_{t}$ represents the reservation price, i.e. the price at which the technology have a zero net gain, for the individuals who gets the treatment in time period $t\left(U_{t}\right.$ is a subset of $D_{t}\left(U_{t} \subseteq D_{t}\right)$ and $U_{t}=D_{t}$ if the individuals with highest benefits gets the technology). 